\title{
MINUTE ROTIFER DARI PERAIRAN ESTUARI SULAWESI UTARA DAN POTENSINYA SEBAGAI PAKAN LARVA IKAN
}

\author{
(Minute rotifers from estuarine waters in North Sulawesi, Indonesia, \\ and their potentials as starting food for fish larvae)
}

\author{
Hety B Lahope ${ }^{1,2}$, Stenly Wullur ${ }^{1,3}$, Joice Rimper ${ }^{1,3}$, Henneke Pangkey ${ }^{1,3}$ \\ dan IFM Rumengan ${ }^{1,3}$ \\ ${ }^{1}$ Program Pascasarjana, PS. Ilmu Perairan, Universitas Sam Ratulangi, Manado, Sulawesi Utara. \\ ${ }^{2}$ Dinas Kelautan dan Perikanan Kab. Kepulauan Talaud, Sulawesi Utara. \\ ${ }^{3}$ Fakultas Perikanan dan Ilmu Kelautan Universitas Sam Ratulangi, Manado, Sulawesi Utara
}

Penelitian ini bertujuan untuk mendapatkan minute rotifer (rotifer berukuran kecil) yang ada di perairan Sulawesi Utara yang memiliki potensi untuk dimanfaatkan sebagai pakan awal larva ikan laut. Sampling rotifer dilakukan di tujuh lokasi estuari yang berbeda dengan menggunakan plankton net (mata jaring $40 \mu \mathrm{m}$ ). Prosedur identifikasi rotifer didasarkan pada tampakan morfologi. Morfometri dilakukan di bawah mikroskop pembesaran 40-100x yang terhubung dengan sebuah komputer untuk visualisasi dan pengukuran. Aiga spesies minute rotifer berhasil diisolasi dari tiga lokasi estuari berbeda. Colurella sp. diisolasi dari sebuah kolam payau (salinitas 25 ppt) yang dipenuhi sampah rumah tangga di Tumpaan Kabupaten Minahasa. Lecane sp. cf Lecane quadridentata (Lecane) diisolasi dari sebuah tambak payau (salinitas $17 \mathrm{ppt)}$ di Meras Kota Manado dan Lecane sp. cf Lecane papuana di muara sebuah sungai kecil (salinitas $<3 \mathrm{ppt}$ ) di Tateli Kabupaten Minahasa. Semua minute rotifer yang ditemukan ini berhasil didomestikasi dan menunjukkan adaptasipositif dalam pemeliharaan berbasis mikroalga. Colurella sp, Lecane sp. cf L. quadridentata dan Lecane sp. ef L. papuana memiliki ukuran panjang lorika (PL) masing-masing $(97,10 \pm 3,58 \mu \mathrm{m}, 130,83 \pm 12,06 \mu \mathrm{m}$ dan 118,70 $\pm 5,46 \mu \mathrm{m})$ sedangkan lebar lorika $(55,37 \pm 2,04 \mu \mathrm{m}, 91,95 \pm 10,58 \mu \mathrm{m}$ dan $101,28 \pm 6,623 \mu \mathrm{m})$ yang secara signifikan lebih kecil dari $B$. rotundiformis (PL 167,41 $\pm 9,10 \mu \mathrm{m}$ dan LL 122,44 $\pm 7,29 \mu \mathrm{m})(\mathrm{p}<0,05)$, sehingga berpotensi untuk dimanfaatkan sebagai pakan awal larva ikan laut yang membutuhkan pakan berukuran lebih kecil.

Kata kunci: minute rotifer, Lecane sp, Colurella sp, larva

This study aims to get minute rotifers (small rotifers) in the waters of North Sulawesi which has the potential to be used as starting food for marine fish larvae. The sampling for rotifers was conducted in seven different estuarine locationsysing plankton net (mesh size $40 \mu \mathrm{m}$ ). Rotifer identification procedure was based on morphological appearances. Morphometric observations were conducted under 40100x magnification microscopeconnected to a computer for visualization and measurement. Three rotifer species were able to be isofated from three different estuarine locations. Colurella sp. was isolated from a brackish pond (salinity of $25 \mathrm{ppt}$ ) which were filled with household garbage in Tumpaan, Minahasa regency. Lecane sp. cf Lecane quadridentata (Lecane) was isolated from a brackish pond (salinity of $17 \mathrm{ppt}$ ) in Meras-Manado and Lecane sp. cf Lecane papuana at the estuary of a small river (salinity $<3 \mathrm{ppt}$ ) in Tateli, Minahasa regency. All minute rotifers were successfully domesticated and showed positive adaptation homicroalgae-based rearing. Colurella sp, Lecane sp. cf L. quadridentata and Lecane sp. cf $L$. paprana have lorica length (PL) of $97.10 \pm 3.58 \mu \mathrm{m}, 130.83 \pm 12.06 \mu \mathrm{m}$, and $118.70 \pm 5.46 \mu \mathrm{m}$, respectively, and lorica width (LL) of $55.37 \mu \mathrm{m} \pm 2.04,91.95 \pm 10.58 \mu \mathrm{m}$, and $101.28 \pm 6.623 \mu \mathrm{m}$. They were significantly smaller than B. rotundiformis (PL of $167.41 \pm 9.10 \mu \mathrm{m}$ and LL $122.44 \pm 7.29 \mu \mathrm{m}$ ) $(p<0.05)$ which are commonly used in larva rearing. Thus these rotifers have potentials to be used as starting food for marine fish larvae that need a smaller size food.

Keywords: Minute rotifer, Lecane sp, Colurella sp, larva

\section{PENDAHULUAN}

Salah satu jenis rotifer yang umum digunakan dalam pemeliharaan larva, khususnya larva ikan laut, adalah rotifer Brachionus plicatilis sp. kompleks (Watanabe et al. 1983; Fukusho et al. 1985). Beberapa alasan penggunaan rotifer dian- taranya karena memiliki kecepatan reproduksi yang tinggi sehingga mudah diproduksi massal (Redjeki, 1999), ukuran tubuh relatif kecil sehingga mudah dimangsa oleh larva (Djarijah, 2010; Mudjiman, 2004) serta kandungan nutrisinya yang dapat dimanipulasi sesuai dengan kandungan nutrisi larva (Purba, 1995; Dhert et al. 2001). Pelaku 
budidaya rotifer membagi $B$. plicatilis $\mathrm{sp}$. kompleks berdasarkan pada tampakan morfologi dan ukuran tubuh ke dalam tiga tipe; SS (super small/sangat kecil) panjang lorika 90-150 $\mu \mathrm{m}, \mathrm{S}$ (small/ kecil) 100-210 $\mu \mathrm{m}$ dan L (large/besar) 130-340 $\mu \mathrm{m}$, (Hagiwara et al. 2001). Secara taksonomi rotifer tipe SS dan S dikategorikan sebagai $B$. rotundiformis sedangkan tipe $\mathrm{L}$ dikategorikan sebagai B. plicatilis (Segers, 1995). Karena ukuran lorikanya yang kecil, $B$. rotundiformis tipe $\mathrm{S}$ dan SS sering digunakan sebagai pakan awal larva ikan laut yang memiliki ukuran bukaan mulut kecil (Fukusho \& Iwamoto, 1980) sedangkan $B$. plicatilis tipe L untuk larva berukuran bukaan mulut lebih besar atau dapat diberikan sebagai pakan alami lanjutan $B$. rotundiformis ketika larva tumbuh lebih besar (Fukusho dan Okauchi, 1982 dalam Redjeki, 1999). Seiring dengan perkembangan teknologi budidaya, beberapa spesies ikan laut tropis seperti; kerapu (Ephinephelus sp., Cephalopholis sp.), napoleon (Cheilinus undulatus), beronang (Siganus sp.) telah dapat dipelihara, dikawinkan dan produksi larvanya dalam kondisi lingkungan terkontrol. Namun, larva yang diproduksi umumnya tidak survive pada tahap awal perkembangan ketika larva mulai mencari makan secara exogeneous (Hunter, 1980. Hagiwara et al. 2001). Larva dilaporkan mati kelaparan meskipun rotifer $B$. rotundiformis tipe SS telah diberikan sebagai pakan awal. Garva diduga membutuhkan pakan awal lebih kecildari ukuran rorifer $B$. rotundiformis tipe SS sebubungan dengan ukuran bukaan mulut lary yang sangat kecil (Slamet and Hutapea_2094).

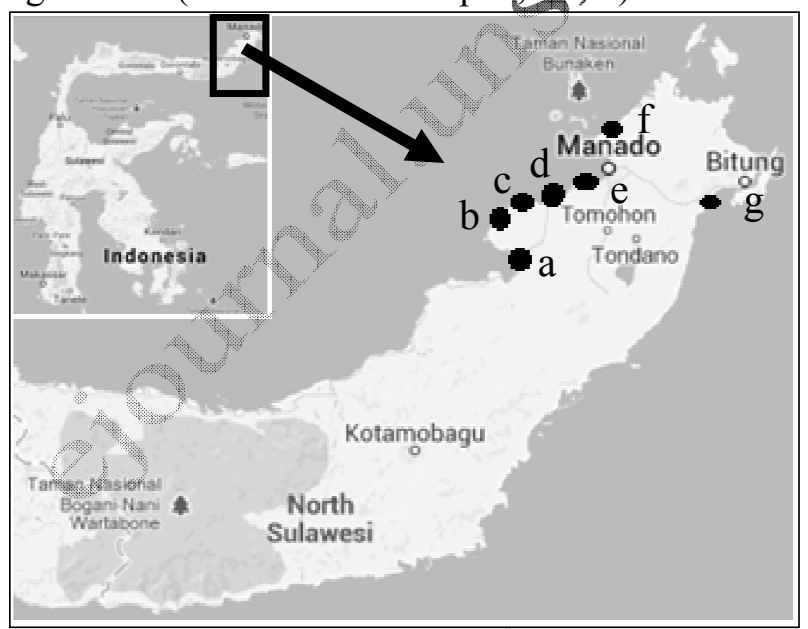

Gambar 1. Lokasi Sampling di beberapa perairan Sulawesi Utara. a). Desa Tumpaan, b). Tanawangko, c). Tateli, d). Tasik Ria, e). Kalasey, f). Meras, g). Manembonembo.

Figure 1. Sampling locations in North Sulawesi waters.
Penelitian ini dilakukan dengan tujuan untuk mendapatkan rotifer yang berukuran lebih kecil dari B. rotundiformis tipe SS untuk dimanfaatkan sebagai organisme pakan alami dalam pemeliharaan larva ikan laut, khususnya yang membutuhkan pakan lebih kecil dari $B$. rotundiformis. Sampling dilakukan di perairan estuari provinsi Sulawesi Utara yang dikenal sebagai daerah yang memiliki keanekaragaman hayati laut tinggi (Warouw, 2010; Rimper, 2008).

\section{METODE PENELITIAN}

Sampel rotifer diisolasi dafi lujü perairan estuari Provinsi Sulawesi Utara (Gambar 1). Sampling dilakukan menggunakan plankton net dengan mata jaring berukuran $40 \mu \mathrm{m}$. Pada kondisi lokasi sampling tertenter dilk kukan dengan bantuan sebuah pompa air ortable. Sampel selanjutnya dibawa ke Raboratorium Bioteknologi Kelautan Fakultás Perrkanan dan Ilmu Kelautan Universitas Sam/Ratulangi Manado untuk dipisahkan dar zooplankton lainnya. Sampel dikelompokan berdasarkan spesies dan didomestikası betbasis pakan mikroalga Nannochloropsis oculata. Prosedur identifikasi spesies dilakukan beydasarkan pada karakteristik morfologi berpedoman pada Fontaneto et al, (2008) dan melalui pencocokan data morfologi rotifer secara online di situs http://rotifer.ansp.org sebanyak 70 individu dewasa dari klon yang sama diawetkan dengan menambahkan formalin $4 \%$ untuk diukur bagian tubuhnya. Rotifer diletakan di bawah sebuah mikroskop yang terhubung dengan komputer untuk visualisasi gambar rotifer. Bagian tubuh rotifer diukur melalui layar visualisasi dengan bantuan software image tool. Bagian-bagian tubuh yang diukur adalah panjang lorika (PL) dan lebar lorika (LL) (Gambar 2). Sejumlah individu rotifer $B$. rotundiformis dewasa strain Poigar diukur dengan prosedur yang sama sebagai pembanding.

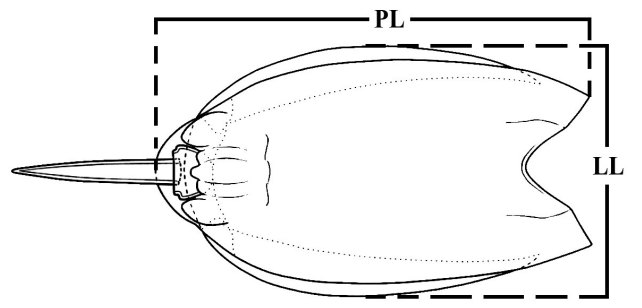

Gambar 2. Prosedur pengukuran bagian tubuh rotifer. PL (panjang lorika) dan $L L$ (lebar lorika).

Figure 2. Measurement of rotifer body part. $P L$ (lorica long) and LL (lorica width). 


\section{HASIL DAN PEMBAHASAN}

Kondisi perairan di tujuh lokasi sampling (Gambar 1) memiliki karakteristik lingkungan yang berbeda-beda. Kolam payau kecil dengan salinitas 25 ppt yang dipenuhi sampah/limbah rumah tangga dijumpai di desa Tumpaan (Gambar 1a), muara sungai besar berair deras berwarna kecoklatan di Tanawangko (Gambar 1b), muara sungai kecil jernih dan berarus lambat di desa Tateli (Gambar 1c), Kawasan mangrove di pesisir desa Tasik Ria (Gambar 1d), muara sungai kecil yang berarus dan sangat keruh di Desa Kalasey, (Gambar 1e), bekas tambak di Desa Meras (Gambar 1f), dan Tambak aktif di Desa Manembo-Nembo (Gambar 1g).

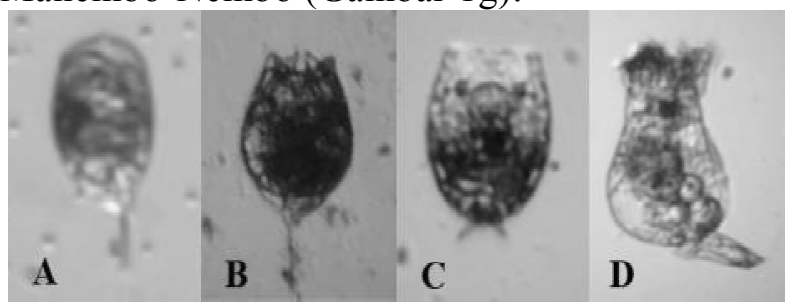

Gambar 3. Minute rotifer yang diisolasi dari perairan estuari Sulawesi Utara. (A) Colurella sp, (B) Lecane sp. cf Lecane quadridentata, (C) Lecane sp. cf Lecane papuana dan (D) B. rotundiformis (no scale).

Figure 3. Minute rotifers isolated from estuaries waters in North Sulawesi.

Hasil analisa sampel dari ke tujuh tøkasi sampling menunjukkan hanya tiga lokasi yakni Tumpaan, Meras dan Tateli yang dijumpariadanya spesies rotifer. Tidak ditemukannya mifer pada lokasi sampling Tanawangko, Tasik Ria, Kalasey dan Manembo-nembo diduga disebabkan diantaranya oleh tingginya kekeruhan dan derasnya arus perairan seperti di Tanawangko dan Kalasey. Kekeruhan disebabkan oleh adanya suspensi/partikel dalam perairan. Kekeruhan yang tinggi dapat mempengaruhi proses filter feeding rotifer, sedangkan arus yang kuat menyulitkan rotifer untuk mempertahankan posisi dalam kolom air (Rodríguez 2004; Nybakken \& Bertness 2005). Selain itu pula tingkat toleransi salinitas beberapa Jentis rotifer bervariasi (Kennish, 1990). Salinitas yang ekstrim dapat menghambat pertumbuhan dan meningkatkan kematian pada zooplankton (Odum, 1993). Perubahan salinitas berpengaruh pada tekanan osmotik sel sehingga menyebabkan plankton harus mempertahankan keseimbangan tekanan osmosis antara protoplasma dengan perairan, oleh karena itu perubahan salinitas yang drastis seperti yang dijumpai di lokasi sampling
Tasik ria diduga mempengaruhi keberadaan rotifer di tempat ini.

Hasil identifikasi spesies dan pencocokan tampakan morfologi menunjukkan bahwa spesies yang ditemukan di Tumpaan adalah Colurella $\operatorname{sp} \operatorname{cf} C$. adriatica (Gambar 3A), sedangkan rotifer yang ditemukan di Meras adalah Lecane sp cf $L$. quadridentata (Gambar 3B) dan di Tateli adalah Lecane sp cf L. papuana (Gambar 3C). Klasifikasi dan karakteristik Colurella sp $\mathrm{cf} C$. adriatica adalah sebagai berikut:

Kingdom : Animalia

Phylum : Rotifera

Class : Monogononta Order : Ploima Family : Lepadellidae Genus : Coluregha Spesies: Golucella sp. cf

Dilihat dari tampakan morfologi Colurella sp cf $C$. adriaticafyang đitemukan ini mirip dengan C. adriatica (Smet, 2005; Fontaneto et al. 2008) yang memilik bentuk tubuh oval hampir setengah lingkaran dan asimetris, kaki pendek dan terdiri dari tiga segmen dengan panjang sekitar seperempat dati panjang tubuh. Tubuh lateral menyerupai kerang (Gambar 3A). Spesies ini memiliki ratarata ukuran panjang lorika 97,10 $\pm 3,58 \mu \mathrm{m}$ yang secara signifikan (t-test $\mathrm{p}<0,05$ ) lebih pendek $41,99 \%$ dibandingkan dengan $B$. rotundiformis yang memiliki panjang lorika $167,41 \pm 9,10 \mu \mathrm{m}$. Rata-rata lebar lorika Colurella sp cf $C$. adriatica adalah $55,37 \mu \mathrm{m}$ yang mana $54,77 \%$ lebih kecil dari $B$. rotundiformis yang memiliki lebar lorika 122,44 $\pm 7,29 \mu \mathrm{m}$. Melalui pengujian statistik didapati bahwa rata-rata ukuran panjang dan lebar lorika Colurella sp. cf $C$. adriatica secara signifikan berbeda dibandingkan B. rotundiformis (t-test $\mathrm{p}<0,05)$. Rata-rata ukuran panjang dan lebar lorika Colurella sp cf $C$. adriatica masih sedikit lebih panjang $(14,52 \%)$ dan lebar $(38,42 \%)$ dibandingkan dengan minute rotifer Proales similis, yang berhasil diisolasi dari perairan Okinawa Jepang (Wullur, et al. 2009; 2011). Spesies kedua yang ditemukan dalam penelitian ini yaitu Lecane sp. $\mathrm{cf}$ L. quadridentata yang diklasifikasikan sebagai:

Kingdom: Animalia

Phylum: Rotifera

Class: Monogononta

Order: Ploimida

Family: Lecanidae

Genus: Lecane

Spesies: Lecane, $\mathrm{sp} \mathrm{cf}$

L. quadridentata. 
Bentuk lorika luas bulat telur, lebarnya sekitar empat-perlima dari panjang, margin anterior bertepatan. Sinus sangat dalam dan berbentuk V, dibulatkan posterior. Tidak ada duri frontal hadir tapi dua segitiga, katup akut terbentuk antara sinus anterior dan tepi lorika. Segmen posterior agak kecil dan memproyeksikan jauh melampaui lempeng dorsal. Kaki panjang dan ramping, sekitar sepertiga dari panjang total, paralel-sisi untuk setengah dari panjang dan meruncing secara bertahap ke titik akut. (Gambar 2B). Dari tampakan morfologinya spesies ini mirip dengan L. quadridentata dengan kisaran ukuran panjang lorika 130,83 $\pm 12,06 \mu \mathrm{m}$ (Gambar 3A) dan lebar lorika $91,95 \pm 10,58 \mu \mathrm{m}$ yang mana panjang lorikanya $21,85 \%$ lebih pendek dan $24,89 \%$ lebih kecil dibandingkan dengan $B$. rotundiformis. Melalui pengujian statistik perbedaan ukuran panjang dan lebar lorika antara Lecane $\operatorname{sp} \mathrm{cf} L$. quadridentata secara signifikan (t-test $\mathrm{p}<0,05$ ).

Spesies Lecane yang teridentifikasi selanjutnya adalah Lecane sp cf L. papuana, yang dapat diklasifikasikan sebagai berikut:

Kingdom: Animalia

Phylum: Rotifera

Class: Monogononta

Order: Ploimida

Family: Lecanidae

Genus: Lecane

Spesies: Lecane sp cf

\section{L. papuana.}

Spesies ini memiliki punggung anterior lebih sempit dari perut dan terdapat elta Kaki yang tidak memiliki duri lateral. Spesies inimemiliki anterior yang sedikit cekung dan ulkuran kaki yang tidak terlalu panjang (Gambar 3C). Dilihat dari tampakan morfologi spesies ini hampir mirip dengan Lecane papuana Muray, 1913 atau yang sering disebut Lecane Juna var. presumpta Ahlstrom, 1938 hanxa saja ukuran dari Lecane luna var. presump lebih besar dari Lecane $\mathrm{sp} \mathrm{cf} L$. papuana xany ditemukan dalam penelitian ini. Rata-rata anjang lorika Lecane sp cf $L$. papuana adalah $118,70 \pm 5,46 \mu \mathrm{m}$ dan lebar lorika 101,28 $\pm 6,623 \mathrm{dm}$ (Gambar 4) yang mana $29,09 \%$ lebih pendek dan $17,28 \%$ lebih kecil dari B. rotundiformis. Uji statistik menunjukkan perbedaan panjang dan lebar yang signifikan dibandingkan dengan $B$. rotundiformis $(\mathrm{p}<0,05)$.

Lecanidae merupakan kelompok rotifer monogononta yang hidup di perairan tawar dan air laut. Genus Lecane merupakan genus paling kaya karena terdiri dari sekitar 200 spesies (Segers, 2007). Penyebaran genus ini melimpah khusus- nya di wilayah pesisir (Segers, 1995). Lecane yang terbaik diantaranya terdapat di Asia Tenggara (Segers, 2001). Pada individu betina dapat dikenal dari struktur kaki dan trofi, namun struktur trofi belum atau jarang digunakan dalam studi taksonomi dari genus (Segers, 1995).

Sachlan (1972) menyatakan bahwa plankton yang hidup pada salinitas $0-10 \mathrm{ppt}$ adalah plankton yang lebih mampu beradaptasi pada lingkungan perairan tawar dan plankton yang hidup pada salinitas 10-20 ppt merupakan plankton yang lebih mampu beradaptasi pada kendisi perairan payau, sedangkan plankton yang hidur pada salinitas yang lebih besar dari 20 pot ädaláh plankton yang lebih mampu beradapta dengan kondisi perairan laut, sehingga dapat disunpulkan bahwa rotifer yang ditemukan di daerah Tumpaan merupakan jenis rotifer yang lebil mampu beradaptasi pada lingkungan perairah laut, rotifer yang ditemukan di Meras merupakan rotifer yang mampu beradaptasi padal perauran payau, sedang rotifer di Tateli merypakan rotifer yang lebih mudah beradaptasi padaperairan tawar karena salinitas perairan padasaat pengambilan sampel rotifer ini adalahe 3 ppt.

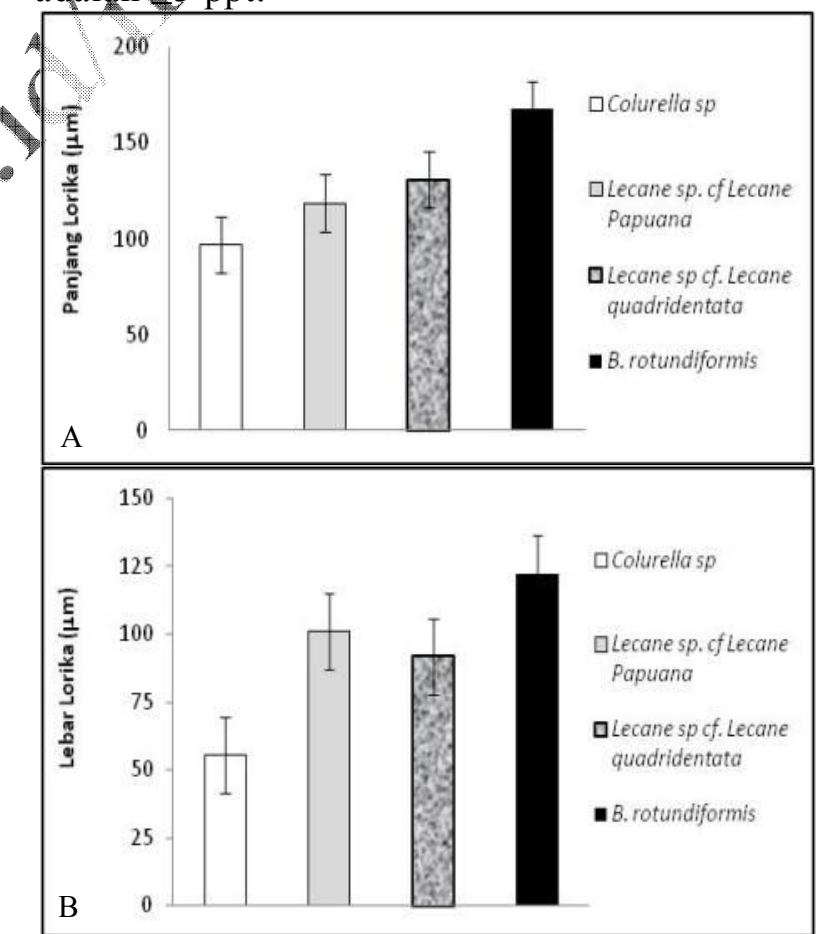

Gambar 4. Rata-rata panjang lorika (A) dan ratarata lebar lorika (B) minute rotifer asal perairan estuari Sulawesi Utara.

Figure 4. Means of lorica length (A) and lorica width (B) of minute rotifers from estuarine waters in North Sulawesi. 


\section{KESIMPULAN}

Tiga spesies rotifer yaitu Colurella sp. cf $C$. adriatica, Lecane sp cf $L$. quadridentata dan Lecane sp cf L. papuana berhasil diisolasi dari tiga lokasi perairan estuari provinsi Sulawesi Utara. Tiga spesies tersebut dapat didomestikasi dan memiliki ukuran tubuh lebih kecil dari $B$. rotundiformis yang merupakan pakan alami konvensional.

\section{DAFTAR PUSTAKA}

Dhert P., Rombaut G., Suantika G. and Sorgeloos P. 2001. Advancement of Rotifer Culture and Manipulation Techniques in Europe. Aquaculture. 129-146.

Djarijah AS. 2010. Pakan Ikan Alami. Kanisius. Yokyakarta. $87 \mathrm{p}$.

Fernando CH. and Zankai NP. 1981. The Rotifera of Malaysia and Singapore with Remarks on Some Species. Journal Hydrobiologia , vol. 78, no. 3, pp. 205-219.

Fukusho K., Okauchi M., Tanaka H., Kraisingdecha P., Wahyuni SI., Watanabe T. 1985. Food value the small SStrain of a rotifer Brachionus plicatilis cultured with Tetraselmis tetrathele for larvae of Black Sea Bream, Acanthopagrus shlegeli. Bull. Nat. Res. Inst. Aquaculture 8: 5-13.

Fontaneto D., De Smet WH. and Melone G. 2008. Identification Key to The Genera of Marine Rotifers Worldwide. Meiofauna Marina, Vol. 16, pp. 75-99, 109.

Fukusho K. and Iwamoto H. 1980. Cyclomorphosis in size of cultured rotifer Brachionus plicatilis. Bull. Nat. Res. Inst. Aquaculture 1: 29-37.

Hagiwara A., Gallardo WG., Assavaaree M., Kotanf (T., de Araujo AB. 2001. Live Food Production In Japan; Recent Progress And Future Aspects. Aquaculture 200

Hunter, J.R. 1980. The feeding behavior and ecology of marine fish larvae, p: 33-77. In J.E. Bardach(Eds.). Fish Behavior and Its Use in the Capturesand Culture of Fishes. ICLARM Conference Proceding.

Kennish MJ. 1990. Ecology of Estuaries. Vol. II: Biological As pects. Florida: CRC Press Inc.

Mudjiman A. 2004. Makanan Kkan. Edisi revisi. Penebar Swadaya. Jakarta. $190 \mathrm{p}$

Nybakken JW, Beftness MD. 2005. Marine Biology: An Ecological Approach. $3^{\text {rd }}$ edition. New York: Pearson Benjamin Cummings.

Odum ER 1993. Dasar-Dasar Ekologi. Yogyakarta. Gajah Mada University Press. Mada
Purba R. 1995. Peningkatan Gizi Rotifera Brachionus plicatilis untuk menunjang pembenihan ikan kakap putih, Lates calcariver dan ikan kerapu macan, Ephinephelus fuscoguttatus. Jurnal Oseana, Vol. XX, Nomor 3: 21-27. ISSN 0261877.

Redjeki S. 1999. Budidaya Rotifera (Brachionus plicatilis). Jurnal Oseana, Volume XXIV, Nomor 2: 27-43. ISSN 0216-1877.

Rimper JRSTL. 2008. Bioekologi dan senyawa bioaktif rotifer Brachionus spp. dari perairan pantai dan estuari Sulawesi Utara. Disertasi. Pascasarjana IPB. Bogor. 183p.

Rodríguez JG. 2004. Intertidal water column meiofauna in relation to wave on an exposed beach. Sci Mar 68 (Suppl. 1): $181-187$.

Sachlan M. 1982. Planktonologi. Directorat Jendtal Perikanan, Jakarta. $140 \mathrm{p}$.

Segers H. 1995. Nomenclature consequences of some recent studies on Brachionus plicatilis (Rotifera, Brachionidae). Hydrobiologia 313/314, 121-122

Segers H. 1995. Zoogeography of tittoral Rotifera, with special reference to the Lecanidae Part II: Morphology and Taxonomy of of Lecane. SPB Academic Publishing.

Segers H. 2001. Zoogeography of the Southeast Asian Rotifera. Hydrobiologia 446/447: 233-246.

Segers H. 2007 Annotated checklist of the rotifers (Phylum Rotifera), with notes on nomenclature, taxonomy and distribution (Zootaxa 1564). Magnolia Press. New Zealand. 104.

Slanet B. and Hutapea JH. 2004. First successful hatchery production of Napoleon wrasse at Gondol Research Institute for Mariculture, Bali. Aquaculture Asia 9, 37.

Smet WHD. 2005. Some Marine Rotifera from Réunion Island, with a Description of a New Species of Lindia Harring and Myers, 1924 and one of Synchaeta Ehrenberg, 1832. Department of Biology, Section Polar Ecology, Limnology and Palaeobiology.

Warouw V. 2010. Memaksimalkan potensi dormansi pada rotifer Brachionus rotundiformius melalui mating experiment. Jurnal Perikanan dan Kelautan. Vol VI. No. 1. 2010. p 31-35.

Watanabe T., Kitajima C. and Fujita S. 1983. Nutritional value of live organism used in Japan for Mass propagation of fishes review. Aquaculture. 34: 115-143.

Wullur S., Sakakura Y., Hagiwara A. 2009. The minute monogonont rotifer Proales similis de Beauchamp : Culture and feeding to small mouth marine fish larvae. Aquaculture, 293(1-2), pp.62-67. 